10 Barrett T, Vaughan Williams C. Use of a questionnaire to obtain an alcohol history from those attending an inner city accident and emergency departhistory from those attending an inner

11 Dent T, Shepherd R, London M, Alexander G, Duff C. Education and audit can improve the identification of excessive drinkers among medical can improve the identification of exces

12 Gentilello LM, Donovan DM, Dunn CW, Rivara FP. Alcohol interventions in trauma centers. Current practice and future directions. $\mathfrak{F} A M A$ 1995;274:1043-8.

13 Cherpitel CJ. Alcohol and injuries: a review of international emergency room studies. Addiction 1993;88:923-37.

14 Holt S, Stewart IC, Dixon JMJ, Elton RA, Taylor TV, Little K. Alcohol and the emergency service patient. BMF 1980;281:638-40.

15 Walsh ME, Macleod DAD. Breath alcohol analysis in the accident and emergency department. Injury 1983;15:62-6.

16 Yates DW, Hadfield JM, Peters K. The detection of problem drinkers in the accident and emergency department. Br f Addict 1987;82:163-7.

7 Redmond AD, Richards S, Plunkett PK. The significance of random breath alcohol sampling in the accident and emergency department. Alcohol Alcoalcohol sampling in th

18 Soderstrom CA, Smith GS. Alcohol's effect on trauma outcomes. A reappraisal of conventional wisdom. $¥ A M A$ 1993;270:93-4

19 Green M, Setchell J, Hames P, Stiff G, Touquet R, Priest R. Management of alcohol abusing patients in accident and emergency departments. $\mathcal{F} R$ Soc Med 1993;86:393-5.

20 Greenspan AJ, Schaal SF. The holiday heart. Electrophysiologic studies of alcohol effects in alcoholics. Ann Intern Med 1983;98:135-9.

21 Brooks SC. Use of cards to offer follow-up to patients seen in an acciden and emergency department with an alcohol related problem. Br f Accid Emerg Med 1987;2:11-13.

22 Freemantle N, Gill P, Godfrey C, Long A, Richards C, Sheldon T, et al. Brief interventions and alcohol use. Effect Health Care 1993;7:1-13.

\title{
Detection of alcohol misusing patients in accident and emergency departments: the Paddington alcohol test (PAT)
}

\author{
S G T Smith, R Touquet, S Wright, N Das Gupta
}

\begin{abstract}
Objective-To develop an effective but practical screening questionnaire for use by accident and emergency (A\&E) staff to detect alcohol misuse early on in its natural history, without unreasonably prolonging patient waiting times; and to integrate an alcohol health worker (AHW) into $A \& E$ to provide counselling for referred patients.

Methods-Two pilot studies for adult patients were undertaken to develop the 1 min Paddington alcohol test (PAT), which has only three compulsory questions for detecting alcohol misuse: two cover peak consumption and frequency of possible binge drinking, and the third asks whether in the patients' view their attendance at A\&E was alcohol related. The use of the PAT was validated in "appropriate" adult patients over a one year period. Patients found to be positive were invited to attend the A\&E review clinic for counselling by the AHW.

Results-The development of the PAT resulted in a referral rate of one patient per $158 \mathrm{~A} \& E$ adult attenders, facilitating a counselling rate of one patient per 263 A\&E adult attenders by the AHW. This counselling rate is a 10-fold increase on the rate of one patient per 2610 adult attenders found in a study undertaken during 1988-90.

Conclusions-The use of the PAT is one practical method for A\&E staff to detect the alcohol misusing patient for referral to a departmental alcohol health worker. (F Accid Emerg Med 1996;13:308-312)

Key terms: accident and emergency; alcohol misuse; alcohol health worker; Paddington alcohol test

The mortality and morbidity from alcohol misuse, with the resulting social and financial cost to society, have been well documented. ${ }^{12}$ The relative cheapness of alcohol because of fiscal policies of postwar United Kingdom governments serves only to exacerbate the problems, ${ }^{34}$ as does conflicting advice from the Department of Health. ${ }^{5}$ This advice has now been clarified by the Chief Medical Officer, and for safe regular consumption the limits remain 21 units per week for men and 14 units per week for women. ${ }^{6}$

Brief interventions with less severely affected misusers of alcohol are worthwhile. ${ }^{7-9}$ This is especially true for patients who have yet to develop physical problems. Overall the effect of brief interventions is estimated to be a $24 \%$ reduction in alcohol consumption. ${ }^{1}$ We have previously shown ${ }^{10}$ that almost half of those patients identified initially in accident and emergency (A\&E) as having an alcohol problem kept an appointment to be screened in a review clinic and, if appropriate, to be given a "same week" appointment with a psychiatrist (table 1). This suggested that $A \& E$ departments are an appropriate place for detection and referral, and helped facilitate the creation of the post of an alcohol health worker-AHW. ${ }^{11}$

In our original work we used a combination of the brief Michigan alcoholism screening test $(\mathrm{MAST})^{12}$ and the CAGE questionnaire, ${ }^{13}$ since questioning patients is the most effective method of screening for alcohol misuse. ${ }^{8} 14$ However, neither of these questions daily alco- 
able 1 Results of first study by Green et al, ${ }^{10}$ two pilot studies, and further one year use of PAT

\begin{tabular}{|c|c|c|c|}
\hline tudy period & Total No of adult patients attending $A \mathcal{E} E$ & $\begin{array}{l}\text { No referred (referral date) - } \\
\text { patient accepting referral }\end{array}$ & Total No counselled (counselling rate) \\
\hline $\begin{array}{l}11.88-31.10 .90 \\
\text { ilot } 125-31.7 .94 \\
\text { ilot } 23-16.8 .94\end{array}$ & $\begin{array}{l}125280 \text { St Mary's and St Charles' } \\
1124 \text { St Mary's } \\
\text { "Minor" } 1504 \\
\text { "Major" } 589 \\
\text { Total } 2093 \text { St Mary's }\end{array}$ & $\begin{array}{l}104(0.08 \%) 1 \text { in } 1205 \\
10(0.89 \%) 1 \text { in } 112 \\
\text { For "minor" condition } 16 \\
\text { For "major" condition } 3 \\
\text { Total } 19(0.91 \%) 1 \text { in } 110\end{array}$ & $\begin{array}{l}\text { By psychiatrist "same week" } 48(0.04 \%) 1 \text { in } 2610 \\
\text { By AHW } 5(0.44 \%) 1 \text { in } 225 \\
\text { By AHW } \\
\text { For "minor" condition } 5 \\
\text { For "major" condition } 3 \\
\text { Total } 8(0.38 \%) 1 \text { in } 261\end{array}$ \\
\hline 'se of PAT 1.9.94-31.8.95 & 53090 St Mary's & $335(0.63 \%) 1$ in 158 & By AHW $202(0.38 \%) 1$ in 263 \\
\hline
\end{tabular}

HW, alcohol health worker; PAT, Paddington alcohol test.

hol intake or binge drinking. Barrett and Vaughan Williams, ${ }^{15}$ using the York Questionnaire- which combines questions on binge drinking with $\mathrm{CAGE}^{16}$-found that $13.3 \%$ of male and $3.3 \%$ of female $A \& E$ attenders admitting to drinking more than 36 and 24 units of alcohol per week, respectively. On the other hand Yates et al ${ }^{17}$ considered the length of alcohol questionnaires to be too onerous to impose on the severely ill or injured patient in the unstructured environment of A\&E. This, combined with pressures created by patient waiting times, ${ }^{8}$ has-as far as we know-prevented any of these questionnaires from being used at present in any $A \& E$ department in the United Kingdom.

Therefore with the appointment of the AHW we asked the question, how were we to proceed in order to improve on our initial low referral rate of 1 in 1205 (table 1)? How could we detect the alcohol misusing adult patient more effectively as part of our ongoing work practice, without unreasonably prolonging patient waiting times? This paper describes our two pilot studies and the development of our alcohol screening and counselling service.

\section{Methods}

Our original work from 1988-1990 covered two inner city hospitals in London, St Mary's, W2 and St Charles', W10, and has been well documented. ${ }^{10}$

At the start of this new work in 1994, carried out solely at St Mary's, W2, two sequential pilot studies were undertaken to develop an effective but brief alcohol misuse questionnaire to be used by $A \& E$ staff for the subsequent study period of 12 months. During both pilot studies all A\&E doctors were asked to complete a questionnaire for every adult attender (16 years of age and above) "if at all possible". For the pilot and subsequent studies the AHW attended each daily $A \& E$ review clinic in order to carry out both screening and counselling of patients referred by $A \& E$ staff. Both the psychiatrist in the original work ${ }^{10}$ and the AHW wrote to all non-attenders offering a further appointment.

\section{FIRST PILOT STUDY}

The first pilot questionnaire highlighted the importance of the initial assessment of the Glasgow coma score and whether the patient was orientated in time, place, and person. At the conclusion of the consultation, excluding those patients who denied drinking alcohol at all, questions concerning alcohol misuse were asked: two covered peak consumption and the frequency of possible binge drinking, one was based on CAGE (an acronym of Cut down, Annoy others, feel Guilty, Eye opener), and one on whether in the patients' view their attendance at $\mathrm{A} \& \mathrm{E}$ was alcohol related. $\mathrm{Pa}-$ tients who were judged to be experiencing difficulties with alcohol were then asked if they wished to see the AHW. Those patients who did not, but appeared to be at risk from alcohol misuse, were given an alcohol advice card in case they changed their mind (perhaps when sober) and wished to attend at a later date. The first pilot was run for the final week (2531.7.94) of the six month term for a 12 member team of $A \& E$ senior house officers, and also for the department's three middle grade staff and two consultants, each $A \& E$ doctor having attended a briefing session on the use of the questionnaire. However, the staff estimated that this questionnaire took two minutes or more to complete in at least $50 \%$ of patients.

\section{SECOND PILOT STUDY}

The second pilot was run over a two week period (3-16.8.94) covering the start of the next team of $12 \mathrm{~A} \& \mathrm{E}$ senior house officers. The new team were given one hour of education covering alcohol misuse. Patients were now assessed by two different methods, depending on whether they were triaged by the nursing staff as "major" (needing to be initially managed on a trolley) or as "minor" (not in need of a trolley). Patients triaged as major were assessed by $A \& E$ doctors as for the first pilot except that the quantity of alcohol drunk was recorded in measures (home or pub) to be later converted to units by the AHW, and the CAGE questions were made optional. Patients who were triaged as minor were given an equivalent self completion questionnaire, including CAGE, by the reception staff which was then collected by the appropriate $A \& E$ doctor.

DEFINITIVE STUDY

The results of these two pilot studies (detailed below) led to the development of the final questionnaire: the one minute Paddington alcohol test (PAT), which was then used for 12 subsequent months with the object of detecting as many adult patients as possible for subsequent referral to the AHW. Alcohol advice cards recommending counselling with the AHW (or contacting Alcoholics Anonymous or Drinkline) were given to patients where possible if the PAT was positive but the patient refused initial referral. Negative PATs were not collected. 


\section{ST MARY'S ACCIDENT \& EMERGENCY DEPARTMENT \\ CONFIDENTIAL FOR A\&E/ALCOHOL STAFF ONLY \\ The One Minute PAdDINGTON AlCOHOL TEST (P.A.T.)}

TO BE KEPT IN MAJOR AND MINOR AREAS. PLEASE COMPLETE FOR ALL A\&E PATIENTS WHERE THERE IS ANY SUSPICION OF ALCOHOL ABUSE e.g. falls, assaults, head injuries, gastrointestinal problems, "unwell", fits, blackouts, collapse, insomnia, sweating, palpitations, chest pain, gout, rashes, depression, overdoses and especially REPEAT ATTENDANCE perhaps with unexplained symptoms and DELAYED ATTENDANCE, perhaps as intoxicated at the time of incident.

Remember the ELDERLY presenting with: falls, confusion, incontinence and self-neglect.

DATE:

PATIENT IDENTIFICATION STICKER:

TIME:

1. 'Quite a number of people have times when they drink more than usual; what is the most you will drink in any one day? NB Please note if home or pub measures. (Units, relating to pub measures, are shown in brackets).

TYPE OF DRINK

Beer/lager/cider

Strong Beer/lager/cider

Wine

Fortified Wine (Sherry, Martini)

Spirits (Gin, Whisky, Vodka)

\section{AMOUNT}

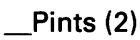

_Pints (5)

Cans (1.5)

_Cans (4)

_Glasses (1.5) _Bottles (9)

_Glasses (1) _Bottles (12)

_Singles (1) _Doubles (2) _Bottles (30)

2. If this is 10 units for a man, or 6 units for a woman, or more: Does this happen: less than once a month?

between once a month and once a week? once a week or more?

(Please record only one YES)

YES/NO

YES/NO

YES/NO

3. 'Do you feel your current attendance in A\&E is related to alcohol?

YES/NO

'Would you like to see our Health Worker?'

YES/NO

If YES, give Alcohol Advice Card and appointment for Review Clinic as per the alcohol referral guidelines

If YES, and patient is admitted, state ward.

\section{DOCTORS SIGNATURE:}

\section{DOCTORS STAMP:}

If NO to this offer of help, but you feel that the patient would benefit from referral, please give Alcohol Advice Card (patient may change mind later, and return)

Even if the patient does not want help now please if possible still complete the form and place in Alcohol box for information.

Please also inform the General Practitioner. Thank You.

The one minute Paddington alcohol test (PAT).

The PAT omitted the Glasgow Coma Score as it was now to be used selectively for "appropriate adult patients" only, that is, those where there was a suspicion of alcohol misuse generated by presentations such as falls, assaults, head injuries, gastrointestinal problems, "un- well", fits, blackouts, collapse, insomnia, sweating, palpitations, chest pain, gout, rashes, depression, overdose, and especially repeated attendances, perhaps with unexplained symptoms and delayed attendance perhaps because intoxicated at the time of the incident. The 
CAGE was left as an optional extra on the PAT questionnaire.

\section{Results}

The original work in 1988-90, using the combination of brief MAST and CAGE, detected 104 patients, 48 of whom were referred to a psychiatrist (table 1). Given the A\&E workload, these figures represent $0.08 \%$ and $0.04 \%$ respectively adult attenders, a minute proportion of potential alcohol misusers.

The results of the two pilot studies were remarkably similar (table 1). Year long use of the PAT detected 335 patients who accepted referral from $53090(0.63 \%)$ adult attenders (16 years of age and older), a referral rate of 1 in 158-a somewhat lower rate than in the pilots, but the final counselling rate of 1 in 263 was 10 times greater than it had been in 198890 ( 1 in 2610), that is, in the absence of an AHW. For the year long use of the PAT it was estimated by the majority of $A \& E$ doctors (self timing) that the PAT took approximately one minute or less to complete, excluding CAGE, for more than $50 \%$ of completed questionnaires.

The percentage of patients who reattended for counselling from the two triage categories of "majors" and "minors" was almost identical (table 2). Of the patients counselled by the AHW, $71 \%$ were referred by senior house officers compared to the smaller number of referrals made by other health workers (table 3 ), but the former comprised an even higher percentage $(91 \%)$ of those that did not reattend (where the source of referral was known). The high percentage of referrals from senior house officers was probably because they were the focus for the education and briefing. The relative inexperience and youth of the senior house officers-thereby conveying less authority-may explain the higher percentage their patients not attending for counselling.

The four optional CAGE questions were completed in $74 \%$ of 306 PATs (29 PATs were either not completed or were mislaid) for patients accepting referral. The CAGE was positive-for two or more stems-in all but $8 \%$ of the total. However, review of all of the completed PATs showed that the use of the optional CAGE questions did not detect any patient who had not already been detected as misusing alcohol by the first three questions of the PAT.

Twenty one of the 202 attendances for counselling were the result of 129 letters sent to patients who did not initially return. Such letters were not sent to 26 patients of no fixed abode and to two living more than 10 miles away. Three patients with a positive PAT who

Table 3 The source of referral of the 335 patients referred to the alcohol health worker

\begin{tabular}{lcc}
\hline Health worker & Counselled & Not counselled \\
\hline A\&E senior house officer & 144 & 108 \\
A\&E middle grade doctor & 11 & 2 \\
A\&E consultant & 8 & 3 \\
A\&E General practitioner & 7 & 4 \\
Other specialty doctor & 22 & 2 \\
Liason psychiatric nurse & 3 & Nil \\
Triage nurse & 7 & Nil \\
Total & 202 (incl 3 not referred) & 119 (14 not recorded) \\
\hline
\end{tabular}

Table 2 Triage categorisation of the 338 patients referred to and/or seen by alcohol health worker

\begin{tabular}{lccc}
\hline Triage category & & Counselled & $\begin{array}{l}\text { Not } \\
\text { counselled }\end{array}$ \\
\hline "Major" patients & 192 & $117(61 \%)$ & 75 \\
"Minor" patients & 146 & $85(58 \%)$ & 61 \\
Total & 338 & 202 (inc 3 not referred) & 136 \\
\hline
\end{tabular}

refused initial referral subsequently attended for counselling. The number of PAT positive patients not accepting referral who never returned was not recorded because the PATs were either not satisfactorily completed or not retained; these were not sent a further letter.

\section{Discussion}

The referral rate to the AHW for both our pilot studies was disappointingly low considering that staff were asked to complete a questionnaire for all adult patients seen "if at all possible". With the second pilot, where the patients with a minor triage category were asked to complete the questionnaire, non-completion was perhaps because of alcohol misuse itself. ${ }^{18}$ Time spent by reception staff explaining to patients the need to complete the questionnaire was also a problem; many patients were multicultural, and were attending for a reason that had interrupted the progress of their day or night, with resulting stress to all concerned. It therefore became apparent that it was not a feasible long term option for the patients to complete the questionnaire themselves.

The use of CAGE did not increase the referral rate to the AHW. Alcohol misuse was detected by the three questions covering quantity drunk, frequency of such drinking, and its relation to $A \& E$ attendance. CAGE was therefore not necessary for the detection of alcohol misuse in A\&E. Barrison et al ${ }^{19}$ also found that CAGE on its own detected very few abnormal drinkers missed by consumption questions. The CAGE will therefore be omitted from future editions of the PAT (figure).

The main reason why doctors failed to complete the questionnaires was time constraint. Barrett and Vaughan Williams ${ }^{15}$ stated that the York questionnaire used at the Royal London Hospital took only two minutes to complete, similar to our first pilot. However, if every $A \& E$ attender were to answer this questionnaire, with 150 adult attenders a day this would add about 35 hours work to each working week, almost enough to justly one additional senior house officer. The PAT had to be simpler than the York questionnaire in order to be completed within one minute in approximately $50 \%$ of patients questioned. While this completion speed was achieved, it was obvious that to complete a PAT for every patient was impossible because of the stress that resulted.

How then can $A \& E$ doctors be best educated to use the PAT selectively for "appropriate" patients only, without missing possible alcohol misuse? Doctors are bad at taking alcohol histories ${ }^{20}$ but improve with the aid of a simple questionnaire plus encouragement, ${ }^{19}$ education, and audit. ${ }^{21}$ Rowland et al ${ }^{22}$ suggest that it is not unfavourable attitudes towards 
alcohol but doctors' perception of their role which determines their treatment of problem drinkers; there seems to be an unspoken assumption that physicians should only concern themselves with the diseases caused by alcohol misuse rather than having an obligation to look after all patients who misuse alcohol. ${ }^{23}$ The importance of detection early on in the natural history of alcohol misuse is not generally appreciated.

Misuse may be obvious; for instance within our own department Williams et al ${ }^{24}$ found that over $50 \%$ of adult head injuries requiring admission were overtly intoxicated by alcohol. Certain situations, as delineated on the PAT questionnaire, must stimulate immediate clinical suspicion; this applies particularly to repeat attendance, where the potential for medicolegal pitfalls is well documented. ${ }^{25}$ Even so there will be many occasions where alcohol misuse is not detected. ${ }^{21}$ It is natural for inexperienced, anxious A\&E senior house officers to concentrate on the reason why a patient has come to $\mathrm{A} \& \mathrm{E}$ as opposed to considering such underlying pathology as alcohol misuse. To counter this we provided each new team of senior house officers with one hour of education on alcohol misuse, emphasising early detection in the course of its natural history, the use of the PAT, and the role of the AHW. Every senior house officer had to complete five PATs within the first week, even if the results did not warrant referral. The questionnaires were then reviewed by an A\&E consultant and the AHW. Each month a league table of referrals was produced and the importance of detecting the alcohol misuser reiterated. The AHW attended each daily review clinic, and therefore had a high departmental profile for ongoing reinforcement and feedback to all A\&E staff, nurses included.

In order for The health of the nation targets for alcohol misuse to be met ${ }^{26}$ patient attendance at $A \& E$ must be included among the opportunities for detection so that appropriate counselling can be given. Liaison with $A \& E$ departments for patients with alcohol problems is an important component for purchasers to build into their contracts with mental health units. ${ }^{27}$ While it cannot be expected that $A \& E$ doctors and nurses will undertake counselling, only they are in a position to undertake the initial detection and referral. Liaison between different disciplines is also essential to improve the service for people whose health is at risk of being damaged by alcohol. ${ }^{28}$

Our study shows that the PAT can provide a sufficient number of appropriate referrals (335) and subsequent attendances for counselling (202) from 53090 new adult A\&E patients a year to justify the employment of a part time AHW (27 hours per week). The PAT continues to be part of our general work practice, indicating that successive teams of $A \& E$ senior house officers (and other grades of $A \& E$ doctor) perceive that the benefits to patients outweigh the consequent time penalty (one minute per PAT). A\&E staff become less frustrated by the problem of alcohol misuse as they are able to offer referral to the AHW, therefore becoming less judgmental. The necessity of attending $A \& E$ may bring home to a patient that they have a problem of alcohol misuse which otherwise they would deny. ${ }^{10}$

The outcome for patients counselled by the AHW is now the subject of further study.

We thank Dr Alex Paton for his help and guidance in the preparation of this paper; Raymond O'Connor for his work as Cliniration of this paper; Raymond O'Connor for his work as Clinical Nurse Specialist in Alcohol NW London Mental Health Fothergill and our SHOs of teams 17 and 18, together with our Fothergill and our SHOs of teams 17 and 18 , together with our our nurses, and

1 Nuffield Institute for Health, University of Leeds, Centre for Health Economics, University of York Research Unit Royal College of Physicians. Brief interventions and alcoho use. Effective Health Care No 7,1993.

2 Paton A, ed. $A B C$ of alcohol. London: BMJ Publishing Group, 1994.

3 Godfrey C. Factors influencing the consumption of alcohol and tobacco: the use and abuse of economic models. $\mathrm{Br} F$ Addiction 1989;84:1123-38.

4 Addiction 1989;84:1123-38.

4 Dillner L. Alcohol abuse. BMf 1991;302:859-60.

5 Edwards G. Sensible drinking. BMf 1996;312:1. Chief Medical Officer. Sensible
Department of Health, 1996;9:4.

7 Chick J. Brief interventions for alcohol misuse. $B M \mathcal{F}$ 1993;307:1374.

8 Babor TF, Ritson EB, Hodgson RJ. Alcohol-related problems in the primary health care seeing: a review of early intervention strategies. Br $\mathcal{F}$ Addiction 1986;81:23-46.

9 Chick J, Lloyd G, Crombie E. Counselling problem drinkers in medical wards: a controlled study. $B M F$ 1985;290:965-7.

10 Green M, Setchell J, Hames P, Stiff G, Touquet R, Priest R. Management of alcohol abusing patients in accident and Management of alcohol abusing patients in accident

11 Touquet R, Priest R. Management of alcohol abusing patients in accident emergency departments. $\mathcal{F} R$ Soc Med patients in accid $1994 ; 87: 720$.

12 Pokorny AD, Miller BA, Kaplan HB. The brief MAST: a shortened version of the Michigan Alcoholism Screening Test. Am f Psychiatry 1972;129:342-5.

13 Mayfield D, McLeod G, Hall P. The CAGE questionnaire: validation of a new alcoholism screening instrument. $A m \mathcal{F}$ Psychiatry 1974;131:1121-3.

14 Lockhart SP, Carter YH, Striven AM, Pang KK, McLaughlin J, Baron JH. Detecting alcohol consumption as a cause of emergency general admissions. $\mathcal{f} R$ Soc Med 1986;79:132- 6

15 Barrett TG, Vaughan Williams C. Use of a questionnaire to obtain an alcohol history from those attending an inner city obtain an alcohol history from those attending an inner city 1989;6:34-40.

16 Rowland N, Maynard A, Beveridge A, Kennedy P, Wintersgill W, Stone W. Doctors have no time for alcohol gill W, Stone W. Doctors have

17 Yates DW, Hadfield JM, Peters K. The detection of problem drinkers in the accident and emergency department. $B r f$ Addiction 1987;82:163-7.

18 Robertson CE, Little K, Smith H, Ritson EB. The impact of alcohol on the acute hospital service: patient presentation, admission and the perception of alcohol use in such groups. Alcohol Alcoholism 1989;24:405-8.

19 Barrison IG, Viola L, Mumford J, Murray RM, Gordon M Murray-Lyon IM. Detecting excessive drinking among admissions to a general hospital. Health Trends 1982;14:80-3.

20 Barrison IG, Viola L, Murray-Lyon IM. Do housemen take an adequate drinking history? $B M \mathcal{F} 1980 ; 281: 1040$.

21 Dent T, Shepherd R, London M, Alexander G, Duff C. Education and audit can improve the identification of excessive drinkers among medical inpatients. Health Trends 1995;27:92-7.

22 Rowland N, Maynard A, Kennedy P, Stone W, Wintergill W. Doctors and alcohol screening-the gap between attitudes Doctors and alcohol screening-the gap bet

23 Paton A. Alcohol misuse and the hospital doctor. Br f Hosp Med 1989;42:394-400.

24 Williams RILI, Hittinger R, Glazer G. Resource implications of head injuries on an acute surgical unit. $\mathcal{F} R$ Soc Med 1994;87:83-6.

25 Touquet R, Fothergill J, Harris NH. Accident \& emergency departments: the speciality of accident \& emergency medicine. In: Powers MJ, Harris NH, eds. Medical negligence. London: Butterworth, 1994

26 Department of Health. The health of the nation: a strategy for health in England. London: HMSO, 1992.

27 Department of Health. Key area handbook: accidents. London: HMSO, 1993

28 Rake MO, Spratley TA Alcohol liaison in action. The Canterbury experience. $\mathcal{F} R$ Coll Physicians Lond 1995;29:275-9. 